\title{
Simulation of solvent extraction flowsheets by a global model combining physicochemical and engineering approaches - Application to cobalt(II) extraction by D2EHPA
}

\author{
Alexandre Chagnes* \\ Université de Lorraine, CNRS, GeoRessources, F- 54000 Nancy, France
}

\begin{abstract}
The liquid-liquid extraction of cobalt(II) from an acidic chloride solution by using bis-(2ethylhexyl) phosphoric acid (D2EHPA) diluted in kerosene has been modelled by means of a combination of physicochemical and engineering approaches. This model is able to calculate the performance of solvent extraction flowsheets (residual fraction at the outlet of the flowsheet and concentration factor between the feed solution and eluate) as a function of $\mathrm{pH}$, leach solution flowrate, solvent flowrate and stripping solution flowrate. The influence of these parameters and mixer-settlers arrangements on the performance of eleven flowsheets is discussed.
\end{abstract}

Keywords: Solvent extraction; modelling; cobalt; D2EHPA; chloride

* To whom correspondence should be addressed (alexandre.chagnes@univ-lorraine.fr) 


\section{Introduction}

Solvent extraction is a mature technology used in hydrometallurgy that consists in transferring a solute from an aqueous phase to a non-miscible organic phase. Such a transfer can be achieved by using appropriate solvents usually composed of an extractant solubilised in a diluent (aliphatic or aromatic diluent in most cases), in the presence of a phase modifier in case of third-phase formation (long-chain alcohol, tri- $n$-butylphosphate, etc.) [1]. The goal of solvent extraction is to achieve efficient recovery of targeted metal(s) with high selectivity towards impurities. The success of this operation depends on solvent formulation as well as the choice and the design of the contactors. Many contactor technologies are available to improve the transfer process while reducing the mechanical energy and avoiding phase disengagement issues [2]. Many researches are devoted to solvent formulation and the search for optimal operating conditions and flowsheets to recover selectively targeted metal(s) from more or less complex leach liquors [3]. Conversely, few researches concern the search for new extracting agents for specific applications whereas it is particularly important when commercial reagents are not sufficiently efficient to recover metals from complex media or when they degrade because of chemical instability under hard conditions [4-10]. Modern modelling tools, i.e. Density Functional Theory (DFT), dynamic molecular, Quantitative Properties Structure Relationship (QSPR), thermodynamic or physicochemical models, etc., can guide the chemist in the design of new extracting agents [11]

Few years ago, we published a paper to investigate the possibility of improving uranium recovery in a given plant merely by modifying the flowsheets and operating conditions without significant additional costs [12]. In this work, computer simulations of extraction-stripping processes were performed by using experimental extraction isotherms of uranium(VI) in acidic sulphate media by tri- $n$-octylamine. In particular, the performance of ten flowsheet configurations was calculated as a function of leach solution flowrate, stripping solution flowrate and solvent flowrate. This model was extended by including physicochemical data related to the chemical degradation of extraction solvents. It evidenced the importance of flowsheet configuration on the sturdiness of solvent extraction processes [5]. We also published several papers on the development of physicochemical models capable to predict the variation of extraction efficiency of uranium(VI) as a function of extractant concentration and phosphoric acid concentration [12-15]. Recently, we developed another model to investigate the extraction properties of new extractants for the recovery of cobalt(II), nickel(II) and manganese(II) from 
acidic chloride media $[16,17]$. This model was able to simulate the extraction curves of these metals by cationic exchangers as a function of $\mathrm{pH}$ in acidic chloride media.

In the present paper, the physicochemical model and the engineering model abovementioned have been combined to predict the variation of the liquid-liquid extraction efficiency of cobalt(II) from acidic chloride media by D2EHPA as a function of $\mathrm{pH}$, leach solution flowrate, solvent flowrate, stripping flowrate and flowsheet configuration.

\section{Experimental Section}

\subsection{Material and Methods}

In order to perform liquid-liquid extraction experiments, feed solutions of $\mathrm{Co}(\mathrm{II})$ at $1.17 \mathrm{~g}$ $\mathrm{L}^{-1}\left(0.02 \mathrm{~mol} \mathrm{~L}^{-1}\right)$ were prepared by dissolving the required amount of Cobalt(II) nitrate hexahydrate $\left(\mathrm{Co}\left(\mathrm{NO}_{3}\right)_{2} \cdot 6 \mathrm{H}_{2} \mathrm{O}\right.$, Sigma Aldrich, purity $\left.\geq 98 \%\right)$ in $1 \mathrm{~mol} \mathrm{~L}^{-1}$ hydrochloric acid solution.

Bis-(2-ethylhexyl)-phosphoric acid (Aldrich, purity=97\%) was used without further purification. Extraction solvent was prepared by diluting D2EHPA in kerosene (Sigma Aldrich, reagent grade, low odor) without phase modifier as no third-phase formation was observed.

The extraction properties of D2EHPA towards $\mathrm{Co}(\mathrm{II})$ in acidic chloride media were evaluated by plotting the distribution ratio of $\mathrm{Co}(\mathrm{II})\left[\mathrm{D}_{\mathrm{Co}}\right]$ as a function of $\mathrm{pH}$. The $\mathrm{pH}$ values of the aqueous phases were adjusted by using $\mathrm{NaOH}$ and $\mathrm{HCl}$ (standard solution, Alfa Aesar). Batch experiments were conducted at $25^{\circ} \mathrm{C}$ in a flask containing equal volumes of aqueous and organic phases $\left(10 \mathrm{~mL} ; \mathrm{V}_{\mathrm{org}} / \mathrm{V}_{\mathrm{aq}}=1\right)$. The biphasic system was shaken with a Thermoshaker (Gerhardt) at $100 \mathrm{rpm}$ for 15 minutes. Preliminary experiments on the kinetics of Co(II) extraction by D2EHPA showed that equilibrium was reached in all cases within 5 minutes of contact. After phase separation, the aqueous phase was filtered on nylon filter (VWR, Sartorius $\left.{ }^{\circledR}, 0.20 \mu \mathrm{m}\right)$ and the equilibrium $\mathrm{pH}$ of the aqueous phase was measured.

Metal concentrations in aqueous solutions were determined by ICP-OES (ICAP 6000 Series, Thermo Scientific) at $237 \mathrm{~nm}$ for cobalt after diluting the sample in hydrochloric acid (ICP standard solution, 37\%, VWR). $\mathrm{Co}(\mathrm{II})$ concentration transferred from the aqueous phase into the organic phase was then deduced by mass balance in order to calculate the distribution ratio of $\mathrm{Co}(\mathrm{II})$ and extraction efficiency. Experiments were duplicated and experimental errors on distribution ratios of $\mathrm{Co}(\mathrm{II})$ were estimated to be within $5 \%$. 


\subsection{Model description}

The model developed in this paper aimed at predicting the extraction efficiency of solvent extraction processes for different arrangements of mixer-settlers in series/parallel as a function of $\mathrm{pH}$, leach solution flowrate, solvent flowrate, stripping flowrate. For this goal, the model had to include a physicochemical model that can describe the metal transfer from the aqueous phase into the organic phase as a function of $\mathrm{pH}$ and an engineering model that can predict flowsheet performance as a function of mixer-settlers arrangement and operating parameters such as flowrates of leach solution, stripping solution and extraction solvent.

\subsubsection{Physicochemical model}

The equilibria reported in Figure 1 was used to model the variation of the extraction efficiency of $\mathrm{Co}(\mathrm{II})$ as a function of $\mathrm{pH}$ in an aqueous phase containing $1 \mathrm{~mol} \mathrm{~L}^{-1}$ chloride. The extraction curves were calculated by solving Eqs (1)-(6) with Scilab@ [SciLab, Copyright $($ ] 1989-2005, INRIA ENPC, www.scilab.org.] deduced from the equilibria reported in Figure 1:

$$
\begin{aligned}
& {[\overline{H L}] V_{\text {org }}+2 K_{2}[\overline{H L}]^{2} V_{\text {org }}+3 K_{3}[\overline{H L}]^{3} V_{\text {org }}+\frac{\beta_{1} K_{a}\left[\mathrm{Na}^{+}\right][\overline{\mathrm{HL}}]}{P\left[\mathrm{H}^{+}\right]} V_{\text {org }}} \\
& +2 \beta^{\prime} \beta_{1} \frac{K_{a}\left[N a^{+}\right][\overline{H L}]^{2}}{P\left[H^{+}\right]} V_{\text {org }}+\frac{n \beta_{n} \beta_{1}^{n} K_{a}^{n}\left[\mathrm{Na}^{+}\right]^{n}[\overline{\mathrm{HL}}]^{n}}{P^{n}\left[\mathrm{H}^{+}\right]^{n}} V_{\text {org }} \\
& +2 \frac{K_{\text {ex1 }} K_{a}^{2}\left[\mathrm{M}^{2+}\right][\overline{\mathrm{HL}}]^{2}}{P^{2}\left[\mathrm{H}^{+}\right]^{2}} V_{\text {org }}+\frac{K_{\text {ex }} \beta_{2} K_{a}\left[\mathrm{M}^{2+}\right]\left[\mathrm{Cl}^{-}\right][\overline{\mathrm{HL}}]}{P\left[\mathrm{H}^{+}\right]} V_{\text {org }} \\
& +\frac{K_{a}[\overline{H L}]}{P\left[H^{+}\right]} V_{a q}+\frac{[\overline{H L}]}{P} V_{a q}-[\overline{H L}]_{0} V_{\text {org }, 0}=0 \\
& {\left[N a^{+}\right] V_{a q}+\frac{\beta_{1} K_{a}\left[N a^{+}\right][\overline{H L}]}{P\left[H^{+}\right]} V_{\text {org }}+\frac{\beta^{\prime} \beta_{1} K_{a}\left[N a^{+}\right][\overline{H L}]^{2}}{P\left[H^{+}\right]} V_{\text {org }}+\frac{n \beta_{n} \beta_{1}^{n} K_{a}^{n}\left[\mathrm{Na}^{+}\right]^{n}[\overline{H L}]^{n}}{P^{n}\left[\mathrm{H}^{+}\right]^{n}} V_{\text {org }}-} \\
& {\left[\mathrm{Na}^{+}\right]_{0} V_{a q, 0}=0} \\
& {\left[\mathrm{M}^{2+}\right] V_{a q}+\beta_{2}\left[\mathrm{M}^{2+}\right]\left[\mathrm{Cl}^{-}\right] V_{a q}+\beta_{3}\left[\mathrm{MCl}^{+}\right]\left[\mathrm{Cl}^{-}\right] V_{a q}+\beta_{4}\left[\mathrm{MCl}_{2}\right]\left[\mathrm{Cl}^{-}\right] V_{a q}+} \\
& \frac{K_{e x 1} K_{a}^{2}\left[M^{2+}\right][\overline{H L}]^{2}}{P^{2}\left[H^{+}\right]^{2}} V_{\text {org }}+\frac{K_{\text {ex } 2} \beta_{2} K_{a}\left[M^{2+}\right]\left[C l^{-}\right][\overline{H L}]}{P\left[H^{+}\right]} V_{\text {org }}-\left[M^{2+}\right]_{0} V_{a q, 0}=0 \\
& {\left[\mathrm{Cl}^{-}\right] V_{a q}+\beta_{2}\left[\mathrm{M}^{2+}\right]\left[\mathrm{Cl}^{-}\right] V_{a q}+\beta_{3}\left[\mathrm{MCl}^{+}\right]\left[\mathrm{Cl}^{-}\right] V_{a q}+\beta_{4}\left[\mathrm{MCl}_{2}\right]\left[\mathrm{Cl}^{-}\right] V_{a q}+} \\
& \frac{K_{e x 2} \beta_{2} K_{a}\left[M^{2+}\right]\left[C l^{-}\right][\overline{H L}]}{P\left[H^{+}\right]} V_{\text {org }}-\left[\mathrm{Cl}^{-}\right]_{0} V_{a q, 0}=0 \\
& 2\left[\mathrm{M}^{2+}\right]+\left[\mathrm{MCl}^{+}\right]+\left[\mathrm{Na}^{+}\right]+\left[\mathrm{H}^{+}\right]-\frac{K_{w}}{\left[\mathrm{H}^{+}\right]}-\left[\mathrm{L}^{-}\right]-\left[\mathrm{Cl}^{-}\right]-\left[\mathrm{MCl}_{3}^{-}\right]=0
\end{aligned}
$$




$$
\left[L^{-}\right]=\frac{K_{a}[\overline{H L}]}{P\left[H^{+}\right]}
$$

In these equations, $K_{w}=10^{-14}$ (ion product of water), $K_{a}$ (acid dissociation constant of the extractant), $K_{2}$ (dimerization constant), $K_{3}$ (trimerization constant), $\beta_{1}, \beta_{2}, \beta_{3}, \beta, \beta_{n}, n, K_{\text {ex } 1}$ and $\mathrm{K}_{\mathrm{ex} 2}$ were determined in our previous work (see Table 1) [16, 17]. HL and L- represent the protonated and unprotonated forms of the extractant, respectively. The presence of an overbar means that species are in organic phase while the absence of overbar indicate that species are in aqueous phase.

This model can be used to calculate successfully the variation of the extraction efficiency of $\mathrm{Co}$ (II) by D2EHPA from acidic chloride solution (and therefore the variation of $\mathrm{Co}$ (II) distribution ratio between the extraction solvent and the aqueous phase) as a function of $\mathrm{pH}$ whatever D2EHPA and chloride concentrations (in a restricted range of chloride concentrations since non-ideal behavior model was included in the present model) [Figure 2].

\subsubsection{Engineering model}

The engineering model used the Newton-Raphson method to calculate metal concentration in organic and aqueous phases of each mixer-settler as a function of cobalt concentration in leach solution as well as flowrates of leach solution, stripping solution and extraction solvent in extraction and stripping stages [18].

The following mass-balance equations were used in the model:

$$
\begin{aligned}
& x_{\text {out }, \mathrm{i}}=\mathrm{x}_{\mathrm{in}, \mathrm{i}}-\frac{\mathrm{S}}{\mathrm{F}}\left(\mathrm{y}_{\text {out }, \mathrm{i}}-\mathrm{y}_{\mathrm{in}, \mathrm{i}}\right) \\
& \mathrm{x}_{\text {out }, \mathrm{i}}^{\prime}=\mathrm{x}_{\mathrm{in}, \mathrm{i}}^{\prime}-\frac{\mathrm{S}}{\mathrm{F}^{\prime}}\left(\mathrm{y}_{\text {out }, \mathrm{i}}-\mathrm{y}_{\mathrm{in}, \mathrm{i}}\right)
\end{aligned}
$$

where the subscripts "out,i" and "in,i" correspond to the outlet and inlet flows through the mixer-settler (i), respectively; $x$ and $y$ denote cobalt concentration in the aqueous and organic phases in the extraction stage, respectively; $x$ ' refers to the cobalt concentration in the aqueous phase in the stripping stage while $\mathrm{S}, \mathrm{F}$ and F' represent the organic phase flowrate and the aqueous feed and stripping phase flowrates, respectively. The flowsheets considered in the present work are displayed in Figure 3.

\subsubsection{Input parameters}


The present model requests the extraction isotherm of Co(II) by D2EHPA at any equilibrium $\mathrm{pH}$ in the aqueous phase. Flowrates of leach solution, stripping solution and extraction solvent as well as $\mathrm{pH}$ of leach solution are the main parameters beside the physicochemical parameters used to describe Co(II) extraction by D2EHPA from acidic chloride media (Table 1).

The extraction isotherm is a graphical representation of $\mathrm{Co}(\mathrm{II})$ concentration in the organic phase as a function of $\mathrm{Co}$ (II) concentration in the aqueous phase at constant temperature. The following empirical equation was used to fit extraction isotherms $[5,12]$ :

$[\overline{C o}]=A[1-\exp (-B[C o])]$

Where $[\overline{\mathrm{Co}}]$ and $[\mathrm{Co}]$ represent $\mathrm{Co}(\mathrm{II})$ concentrations in the organic and aqueous phases at the equilibrium, respectively.

The value of A corresponds to Co(II) concentration at the plateau of the extraction isotherm. In the case of $\mathrm{Co}$ (II) extraction by acidic cationic exchangers, A value can be calculated by using Equation (10) derived from the extraction equilibrium reported in Eq. (11) [19]:

$A=\frac{M_{H L}[\overline{H L}]_{0}}{4}\left(\right.$ in $\left.\mathrm{g} \mathrm{L}^{-1}\right)$

where $\mathrm{M}_{\mathrm{HL}}$ and $[\overline{H L}]_{0}$ denote the molecular weight of the cationic exchanger D2EHPA and the initial concentration of D2EHPA, respectively.

$\mathrm{Co}^{2+}+2(\overline{H L})_{2} \rightleftharpoons \overline{\mathrm{CoL}_{2}(H L)_{2}}+2 \mathrm{H}^{+}$

In the case of cationic exchangers, the extraction isotherm depends on $\mathrm{pH}$ since the distribution ratio of $\mathrm{Co}$ (II) changes as a function of $\mathrm{pH}$. The distribution ratio of $\mathrm{Co}$ (II) [ $\mathrm{D}_{\mathrm{Co}}$ ] can be calculated at any $\mathrm{pH}$ by using the above-mentioned physicochemical model.

$B=\frac{D_{C o}(p H)}{A}=\frac{4 D_{C o}(p H)}{M_{H L}[\overline{H L}]_{0}}$

Finally, Equation (12) can be rewritten as follows:

$[\overline{C o}]=\frac{M_{H L}[\overline{H L}]_{0}}{4}\left[1-\exp \left(-\frac{4 D_{C o}(p H)}{M_{H L}[\overline{H L}]_{0}}[C o]\right)\right]$

In this equation, the distribution ratio of $\mathrm{Co}$ (II) between the aqueous phase and the extraction solvent were calculated at any $\mathrm{pH}$ by using the above-mentioned physicochemical model. Figure 4 shows the calculated extraction isotherms of Co(II) by D2EHPA at different $\mathrm{pH}$ in acidic chloride solution. 


\section{Results and Discussion}

The model has been used to investigate the effect of the number of mixer-settlers on flowsheet performance when the $\mathrm{pH}$ in each mixer-settlers is controlled so that it remains constant and equal to $\mathrm{pH} 5$, which corresponds to an extraction efficiency of $95 \%$. The flowsheet performance has been assayed by calculating the residual fraction of metals $\left(f_{r}\right)$ and the concentration factor $\left(f_{c}\right)$ expressed as:

$f_{r}=\frac{x_{\text {out }, \text { extr }}}{x_{0}}$

$f_{c}=\frac{x_{\text {out }, \text { strip }}}{x_{0}}$

where $\mathrm{x}_{0}, \mathrm{x}_{\text {out,extr }}$ and $\mathrm{x}_{\text {out,strip }}$ denote initial cobalt concentration in the leach solution at the entrance of the flowsheet, cobalt concentration at the outlet of the extraction stage (raffinate) and cobalt concentration at the outlet of the stripping stage (eluate).

Figure 5 shows the influence of $\mathrm{S} / \mathrm{F}$ ratio (solvent flowrate over leach solution flowrate) for the flowsheet configurations reported in Figure 3 when $\mathrm{pH}$ values are kept constant in each mixer-settler $(\mathrm{pH}=5), \mathrm{x}_{0}=1.7 \mathrm{~g} \mathrm{~L}^{-1}, \mathrm{x}_{\text {strip }}=0 \mathrm{~g} \mathrm{~L}^{-1}$ (initial cobalt concentration in the stripping solution) and $\mathrm{S} / \mathrm{F}^{\prime}=30$ (solvent flowrate over stripping flowrate ratio). In all cases, an increase of $\mathrm{S} / \mathrm{F}$ ratios at constant $\mathrm{S} / \mathrm{F}$ ' leads to a decrease of both residual fraction and concentration factor. Figure 5a shows an increase of the number of mixer-settlers in the extraction stage is responsible for a drastic decrease of the residual fraction. Conversely, the number of mixersettlers in the stripping stage (comparison of $4 \_2$ and $4 \_3$ ) has no influence on the residual fraction, likely because the $\mathrm{pH}$ of the stripping solution may be sufficiently low to achieve high stripping efficiency with only one mixer-settler. Likewise, there is no significant influence of the number of mixer-settlers on the concentration factor (Figure $5 b$ ). Figures $5 \mathrm{c}$ and $5 \mathrm{~d}$ shows that there is no significant influence of the flowsheet on the residual fraction and the concentration factors whatever S/F values (flowsheets 13_12, 13_21, 22_21,31_12 and 31_21). Furthermore, this Figure shows that the same performance is obtained with the two-loop flowsheets or the one-loop flowsheet 4_3.

The influence of $\mathrm{pH}$, flowrates and mixer-settlers configuration on residual fraction and concentration factor has been investigated (Figure 6). An increase of $\mathrm{pH}$ in the mixers-settlers is responsible for an increase of the concentration factor and a decrease of the residual fraction since metal extraction is more efficient at high $\mathrm{pH}$. It is interesting to highlight that an increase of solvent flowrate is responsible for a significant decrease of the $\mathrm{pH}$ requested to achieve high 
extraction efficiency and high concentration factor. For instance, the $\mathrm{pH}$ of extraction for achieving a residual fraction of 0.02 and a concentration factor around 18.5 can be decreased from 5.2 to 4.5 by increasing the solvent flowrate from $70 \mathrm{~m}^{3} \mathrm{~h}^{-1}$ to $220 \mathrm{~m}^{3} \mathrm{~h}^{-1}$. Therefore, the same performance can be reached by increasing the flowrate while decreasing significantly the $\mathrm{pH}$ in the mixer-settlers, and thus, the operating cost of the process. Furthermore, Figure 7 shows that there is no significant difference in residual fraction and concentration fraction vs. $\mathrm{pH}$ between the flowsheets $2 \_1,3 \_1$ and 4_3. Likewise, comparison of performances ${ }^{\wedge}$ of these flowsheets with flowsheets 3_2 and 4_2 does not show any significant difference (results not shown in this paper).

The variations of the residual fractions and concentration factors as a function of $\mathrm{pH}$ for flowsheets 13_12,13_21,22_12, 22_21, 31_12 and 31_21 are exactly the same (results not shown here). Therefore, changes in mixer-settlers arrangement do not affect flowsheet performances. Conversely, the variation of the residual fraction and the concentration factor as a function of $\mathrm{pH}$ and solvent flowrate for the flowsheets $4 \_3$ and $13 \_12$ are slightly different (Figure 8). Nevertheless, the difference is not high enough to expect any impact on the operating cost of the liquid-liquid extraction process.

Figure 9 shows the influence of cobalt concentration in the leach solution on residual fraction and concentration factor for flowsheets $4 \_3$ as well as 13_12,13_21, 22_12, 22_21,31_12 and 31_21 at $\mathrm{F}=110 \mathrm{~m}^{3} \mathrm{~h}^{-1}, \mathrm{~S}=30 \mathrm{~m}^{3} \mathrm{~h}^{-1}$ and $\mathrm{F}^{\prime}=4 \mathrm{~m}^{3} \mathrm{~h}^{-1}$ when $\mathrm{pH}$ in each mixer-settler is kept equal to 5. This Figure shows that the residual fraction of cobalt is significantly decreased at high cobalt concentration in the leach solution by using the two-loops flowsheets instead of the classical flowsheet 4_3 while the concentration factor remains high. Furthermore, it is interesting to highlight that the same performance is obtained between the flowsheets $13 \_12$, 13_21, 22_12 and 22_21 as well as between the flowsheets 31_21 and 31_12. It appears that the flowsheets 13_12 and 13_21 exhibit the best performance since the concentration factor remains high $\left(f_{c} \sim 25\right)$ and the residual factor remains low even in the presence of $5 \mathrm{~g} \mathrm{~L}^{-1}$ cobalt in the leach solution

\section{Conclusion}

A model combining the physicochemistry of cobalt(II) extraction from acidic chloride media by D2EHPA and an engineering approach has been developed to predict the influence of the chemistry ( $\mathrm{pH}$, metal concentration) and the engineering (mixers-settlers arrangement, flowrates of the leach solution, stripping solution and extraction solvent) on the performance 
of solvent extraction processes. Such a model could be used to optimize solvent extraction processes or to predict the influence of operation conditions on solvent extraction efficiency.

\section{References}

1. Chagnes, A., "Fundamentals in electrochemistry and hydrometallurgy". In: A. Chagnes, J. Swiatowska, éditeurs, Lithium Process Chemistry: Resources, Extractions, Batteries and Recycling. 1st ed. Amsterdam: Elsevier, 2015 (ISBN: 978-0-12-801417-2). p. 4180.

2. Ritcey G. M., Solvent Extraction: Principles And Applications To Process Metallurgy (Vol. 2), G.M. Ritcey \& Associates Incorporated (2006).

3. Habashi, F., Handbook of extractive metallurgy, Wiley VCH, NewYork (1997).

4. Chagnes, A.; Fossé, C.; Courtaud, B.; Thiry, J.; Cote, G. Chemical degradation of the mixture of trioctylamine (extractant) and 1-tridecanol (phase modifier) in acidic sulfate media in the presence of vanadium (V), Hydrometallurgy 2011, 105(3-4), 328-333.

5. Chagnes, A.; Courtaud, B.; Thiry, J.; Cote, G. Computer Simulation of Flow Sheets for the Solvent Extraction of Uranium: A New Route to Delay the Effect of the Chemical Degradation of the Organic Phase on Uranium Recovery from Acidic Sulfate Media”, Journal of Chemical Technology and Biotechnology 2009, 84, 1899-1907.

6. Beltrami, D.; Chagnes, A.; Haddad, M.; Laureano, H.; Mokhtari, H.; Courtaud, B.; Jugé, S.; Cote, G. Development of new cationic exchangers for the recovery of uranium(VI) from wet phosphoric acid, Separation Science and Technology 2013, 48, 480-486.

7. Beltrami, D. Chagnes, A.; Haddad, M.; Laureano, H.; Mokhtari, H.; Courtaud, B.; Jugé, S.; Cote, G. Solvent extraction studies of uranium(VI) from phosphoric acid: role of synergistic reagents in mixture with bis(2-ethylhexyl) phosphoric acid. Hydrometallurgy 2014, 144-145, 207-214.

8. Omelchuk, K.; PSzczepański, P.; Shrotre, A.; Haddad, M.; Chagnes, A. Effects of structural changes of new organophosphorus cationic exchangers on solvent extraction of cobalt, nickel and manganese from acidic chloride media. RSC Advances 2017, 7, $5660-5668$.

9. Turgis, R.; Leydier, A., Arrachart, G. ; Burdet, F.; Dourdain, S. ; Bernier, G. ; Miguirditchian, M. ; Pellet-Rostaing, S. Uranium Extraction from Phosphoric Acid Using Bifunctional Amido-Phosphonic Acid Ligands. Solvent Extraction and Ion Exchange 2014, 32(5), 478-491. 
10. Miguirditchian, M.; Bernier, G.; Pacary, V.; Balaguer, C.; Sorel, C.; Berlemont, R.; Fries, B.; Bertrand, M.; Camès, B.; Leydier, A.; Turgis, R.; Arrachart, G.; PelletRostaing, S.; Mokhtari, H. Development of a new solvent extraction process based on butyl-1-[ N,N -bis(2-ethylhexyl)carbamoyl]nonyl phosphonic acid for the selective recovery of uranium(VI) from phosphoric acid. Solvent Extraction and Ion Exchange 2016, 34(3), 274-289.

11. Chagnes, A.; Moncomble, A.; Cote, G. In-Silico calculations as a helpful tool for designing new extractants in liquid-liquid extraction. Solvent Extraction and Ion Exchange 2013, 31 (5), 499-518.

12. Collet S., Chagnes, A.; Courtaud, B.; Thiry, J.; Cote, G. Solvent Extraction of Uranium from Acidic Sulfate Media by Alamine ${ }^{3} 336$ : Computer Simulation and Optimization of the Flowsheets. Journal of Chemical Technology and Biotechnology 2009, 84 13311337.

13. Beltrami, D.; Cote, G.; Mokhtari, H.; Courtaud, B.; Chagnes, A. Modelling of the extraction of uranium (VI) from concentrated phosphoric acid by synergistic mixtures of bis-(2-ethylhexyl)-phosphoric acid and tri-n-octylphosphine oxide, Hydrometallurgy 2012, 129-130, 118-125.

14. Dartiguelongue, A., Provost, E, Chagnes, A.; Cote, G.; Fürst, W. Experimental determination and modeling of the speciation of Uranium(VI) in phosphoric acid medium. Solvent Extraction and Ion Exchange 2016, 34(3), 241-259.

15. Dartiguelongue, A.; Chagnes, A.; Provost, E.; Cote, G.; Fürst, W. Modelling of uranium(VI) extraction by D2EHPA/TOPO from phosphoric acid within a wide range of concentrations. Hydrometallurgy 2016, 165, 57-63.

16. Omelchuk, K.; Stambouli, M.; Chagnes, A. Investigation of aggregation and acid dissociation of new cationic exchangers for liquid-liquid extraction, Journal of Molecular Liquids Journal of Molecular Liquids 2018, 262, 111-118.

17. Omelchuk, K.; Chagnes, A. New cationic exchangers for the recovery of cobalt(II), nickel(II) and manganese(II) from acidic chloride solutions: Modelling of extraction curves, Hydrometallurgy 2018, 180, 96-103.

18. Ypmat T.J., Historical development of the Newton-Raphson method. SIAM Review 1995, 37, 531-551.

19. Omelchuk, K.. PhD thesis, "Etude physicochimique de nouveaux agents d'extraction pour la récupération du cobalt, du nickel et du manganèse en milieu chlorure par extraction liquide-liquides", PSL University (18 January 2018). 


\section{Acknowledgement}

This work was supported by the French National Research Agency through the national program "Investissements d'avenir" with the reference ANR-10-LABX-21 - RESSOURCES21. 


\section{Tables}

Table 1: Parameters used in the physicochemical model to calculate the variation of the extraction efficiency of Co(II) by D2EHPA from acidic chloride media [16, 17].

\begin{tabular}{cc}
\hline $\mathbf{P}$ & 211 \\
$\mathbf{p K}_{\mathbf{a}}$ & 2.6 \\
$\mathbf{K}_{\mathbf{2}}$ & 184 \\
$\mathbf{K}_{\mathbf{3}}$ & 8385 \\
$\boldsymbol{\beta}_{\mathbf{1}}$ & 8 \\
$\boldsymbol{\beta}$ & 230 \\
$\boldsymbol{\beta}_{\mathbf{n}}$ & $10^{7}$ \\
$\mathbf{n}$ & 7 \\
\hline
\end{tabular}




\section{Figures}

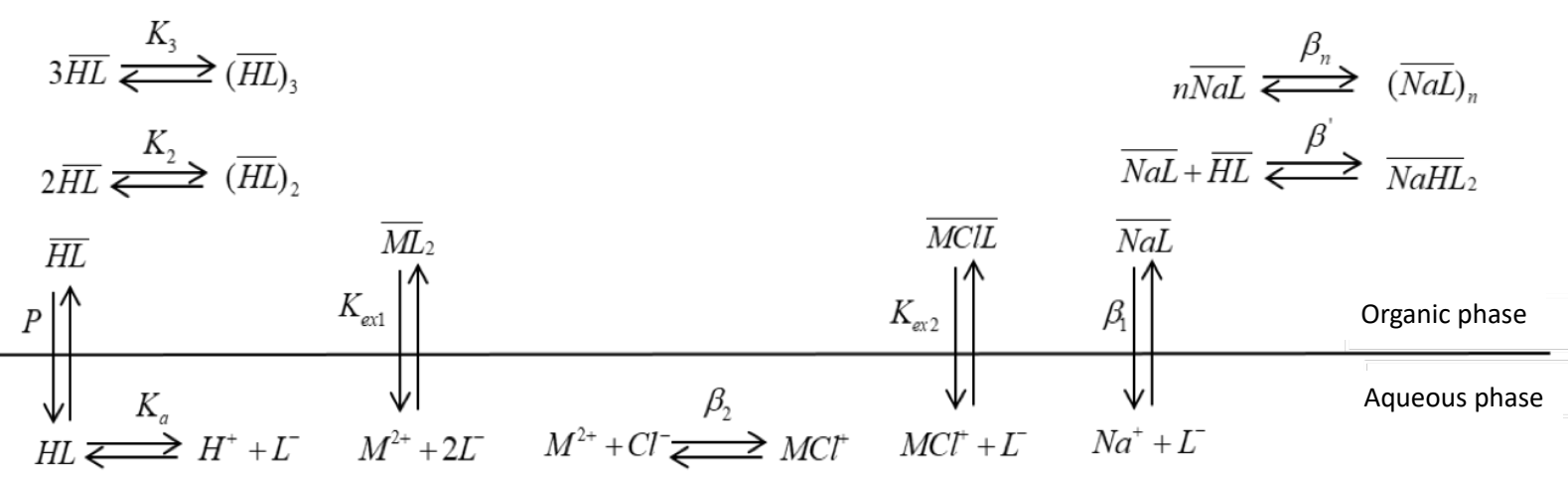

Figure 1: Equilibria implemented in the physicochemical model and the correspoinding equilibrium constants for the calculation of the extraction curves of $\mathrm{Co}$ (II) from acidic chloride media.

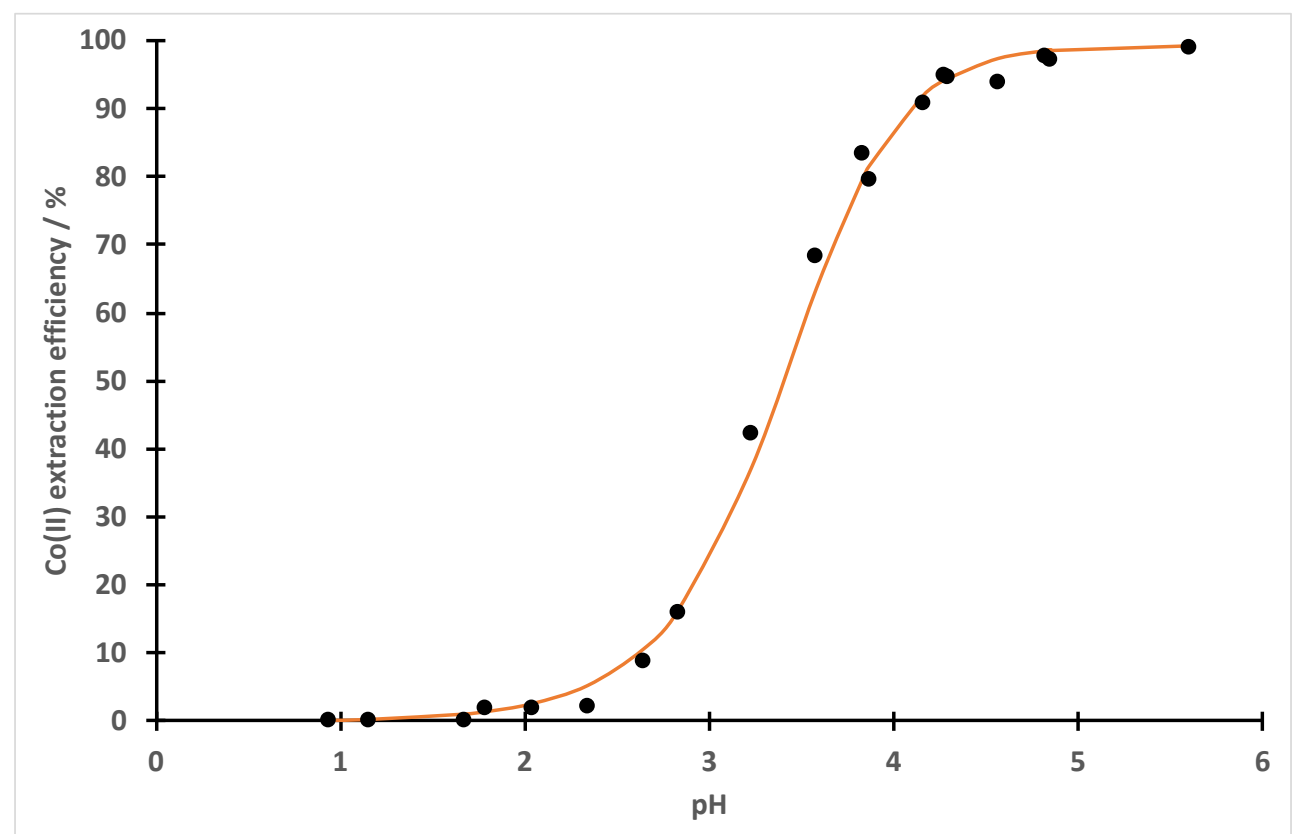

Figure 2: Experimental and calculated extraction curves of $\mathrm{Co}(\mathrm{II})$ by D2EHPA at $25^{\circ} \mathrm{C}$. $[\mathrm{HL}]_{\mathrm{org}, 0}=0.25 \mathrm{~mol} \mathrm{~L}^{-1} ;[\mathrm{HCl}]=1 \mathrm{~mol} \mathrm{~L}^{-1} ;\left[\mathrm{Co}^{2+}\right]_{0}=0.02 \mathrm{~mol} \mathrm{~L}^{-1} \cdot \bullet:$ Experimental data; - : Calculated data from from Eqs (1)-(6) with the physicochemical parameters reported in Table 1. 

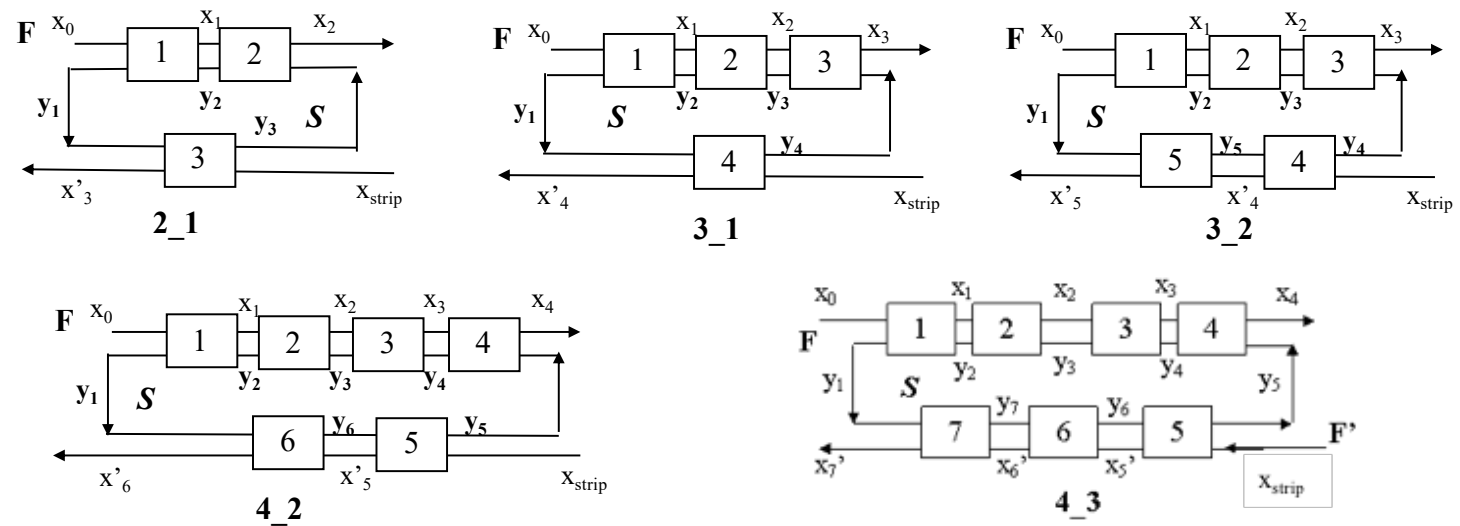

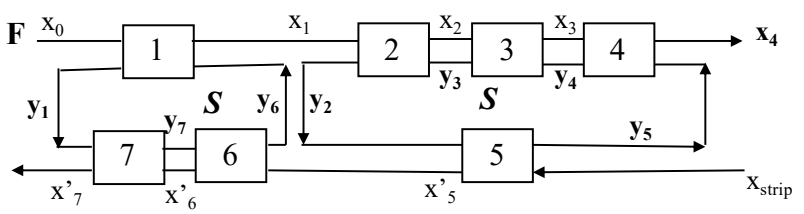

13_21

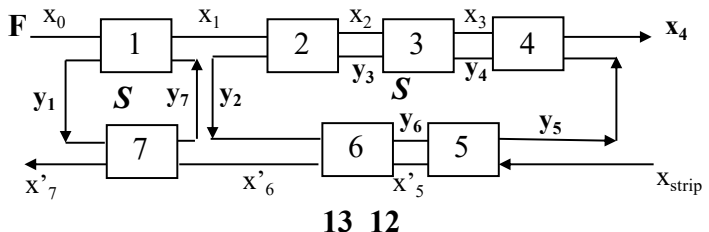

13_12

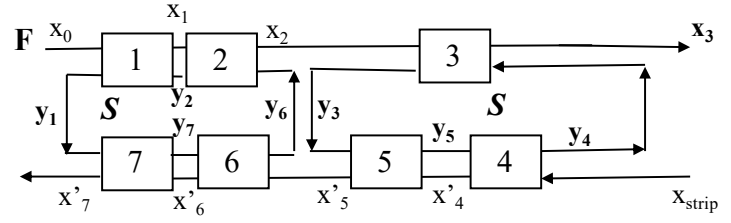

22_12

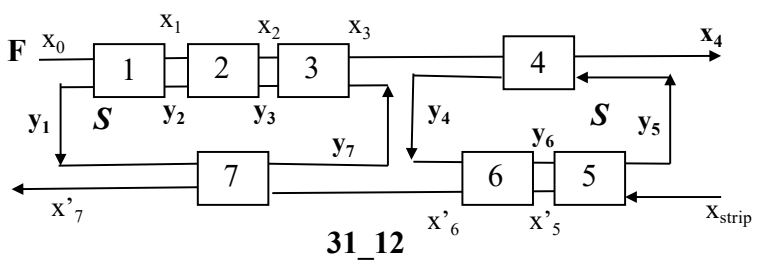

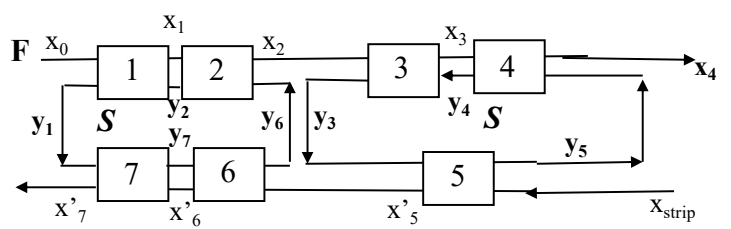

2221

Figure 3: Arrangement of mixers-settlers.

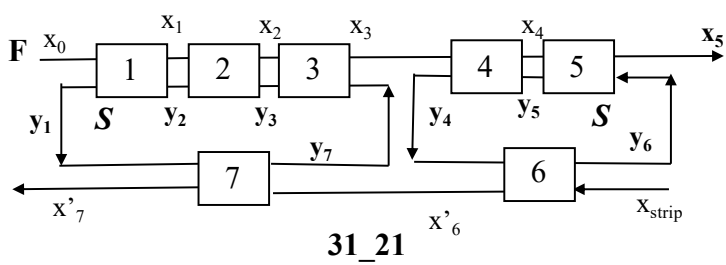




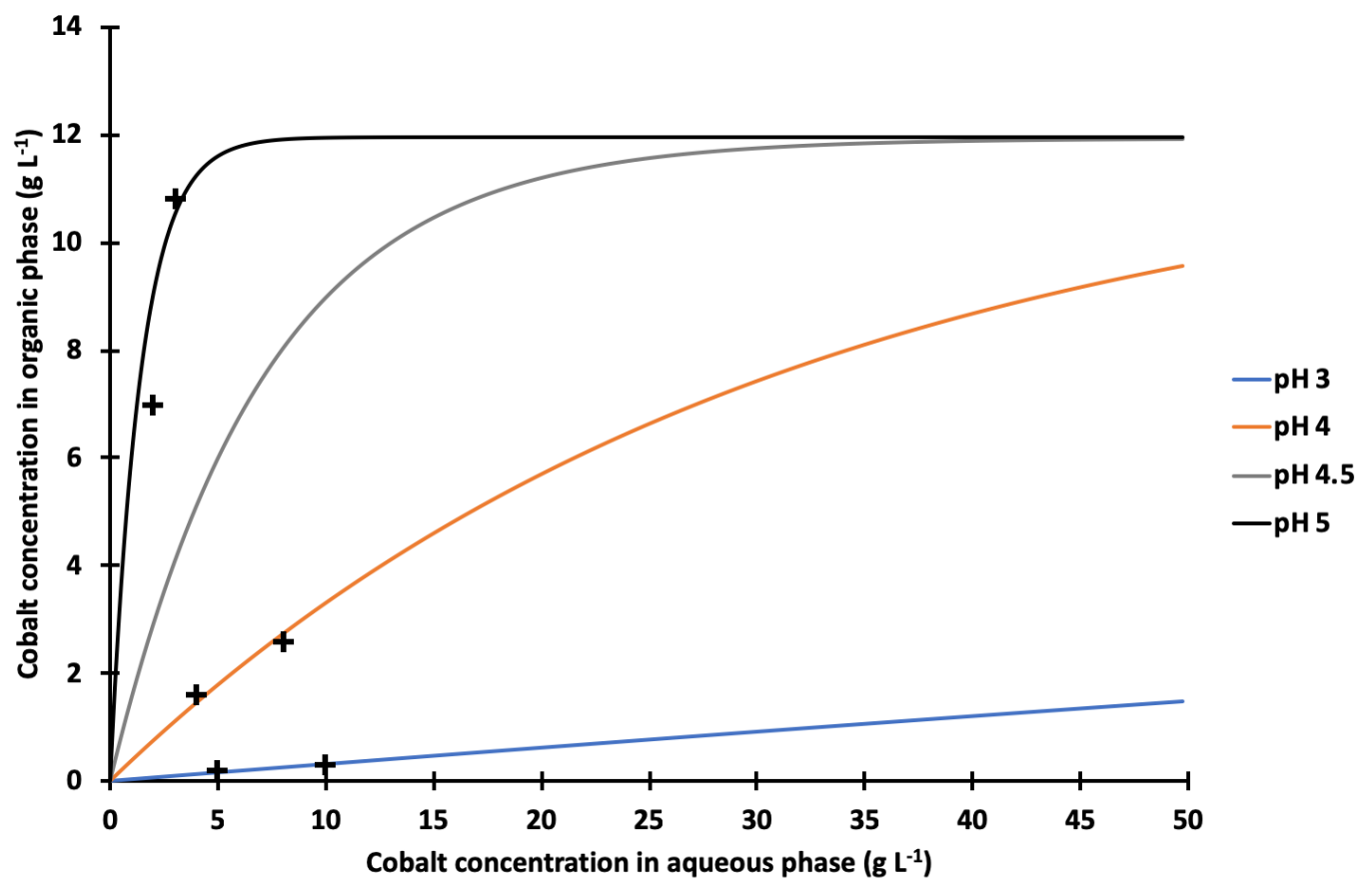

Figure 4: Extraction isotherms of Co(II) by D2EHPA calculated by using Eq. (13) and Eqs (1)(6) with the physicochemical parameters reported in Table 1. $[\mathrm{HL}]=0.25 \mathrm{~mol} \mathrm{~L}^{-1}$; $\left[\mathrm{Cl}^{-}\right]=1 \mathrm{~mol} \mathrm{~L}^{-1}$; temperature $=25^{\circ} \mathrm{C}$. 
(a)

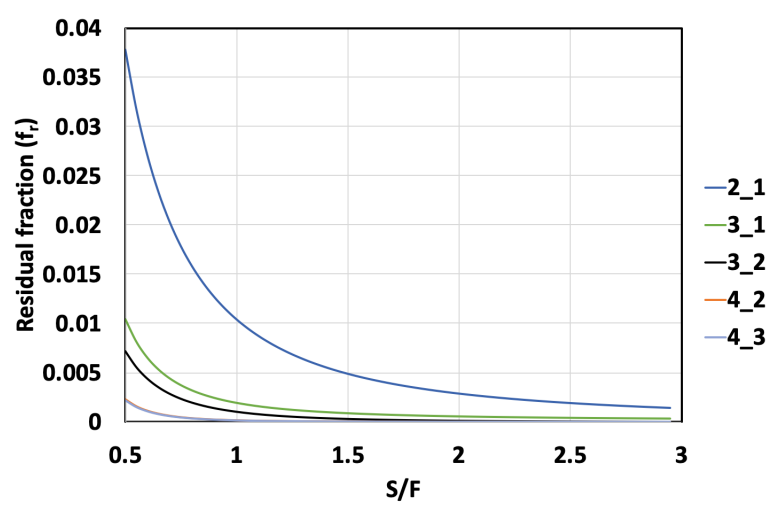

(c)

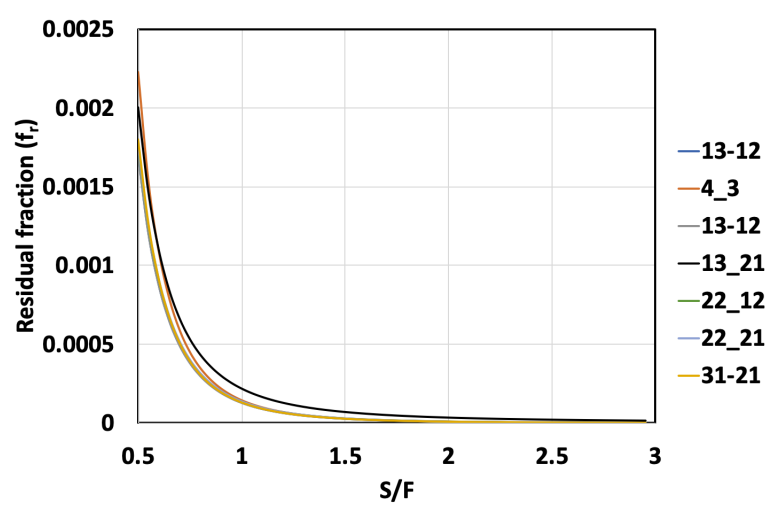

(b)

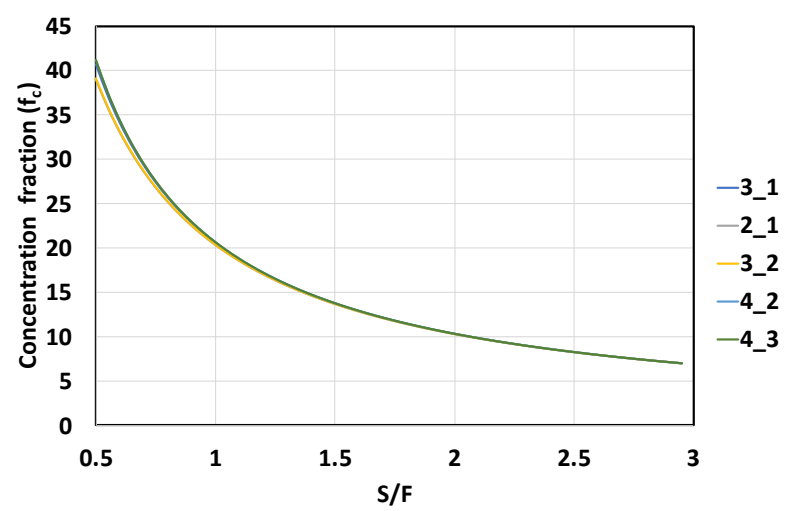

(d)

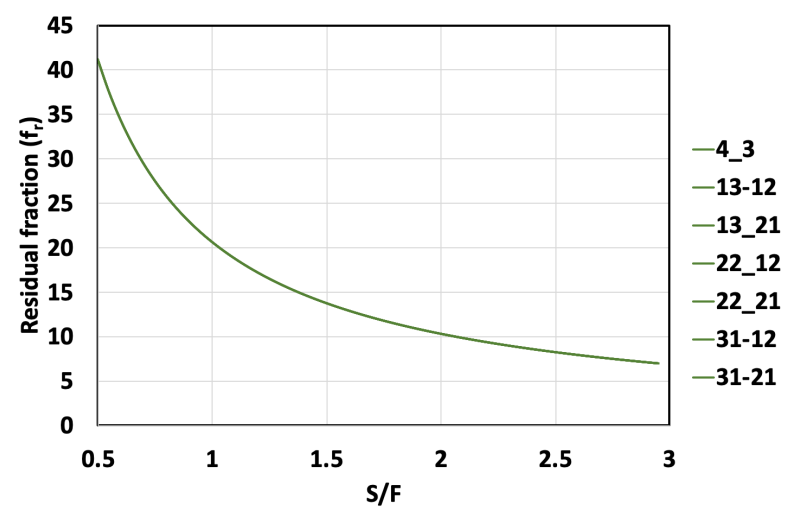

Figure 5: Influence of $\mathrm{S} / \mathrm{F}$ at $\mathrm{pH} 5$ on (a) residual factor $\left(\mathrm{f}_{\mathrm{r}}\right)$ and $(\mathrm{b})$ concentration factor $\left(\mathrm{f}_{\mathrm{c}}\right)$ for flowsheets 2_1, 3_1, 3_2, 4_2 and 4_3 as well as on (c) residual factor $\left(f_{r}\right)$ and (d) concentration factor $\left(f_{c}\right)$ for flowsheets $4 \_3,13 \_12,13 \_21,22 \_12,22 \_21,31 \_12$ and 31_21, respectively. Operating parameters: $\mathrm{x}_{0}=1.7 \mathrm{~g} \mathrm{~L}^{-1} ; \mathrm{x}_{\text {strip }}=0 ; \mathrm{S} / \mathrm{F}^{\prime}=30$; stripping solution: $\mathrm{pH} 1$ and $\left[\mathrm{Cl}^{-}\right]=1 \mathrm{~mol} \mathrm{~L}-1$. Calculated data from from Eqs (1)-(6) with the physicochemical parameters reported in Table 1. 


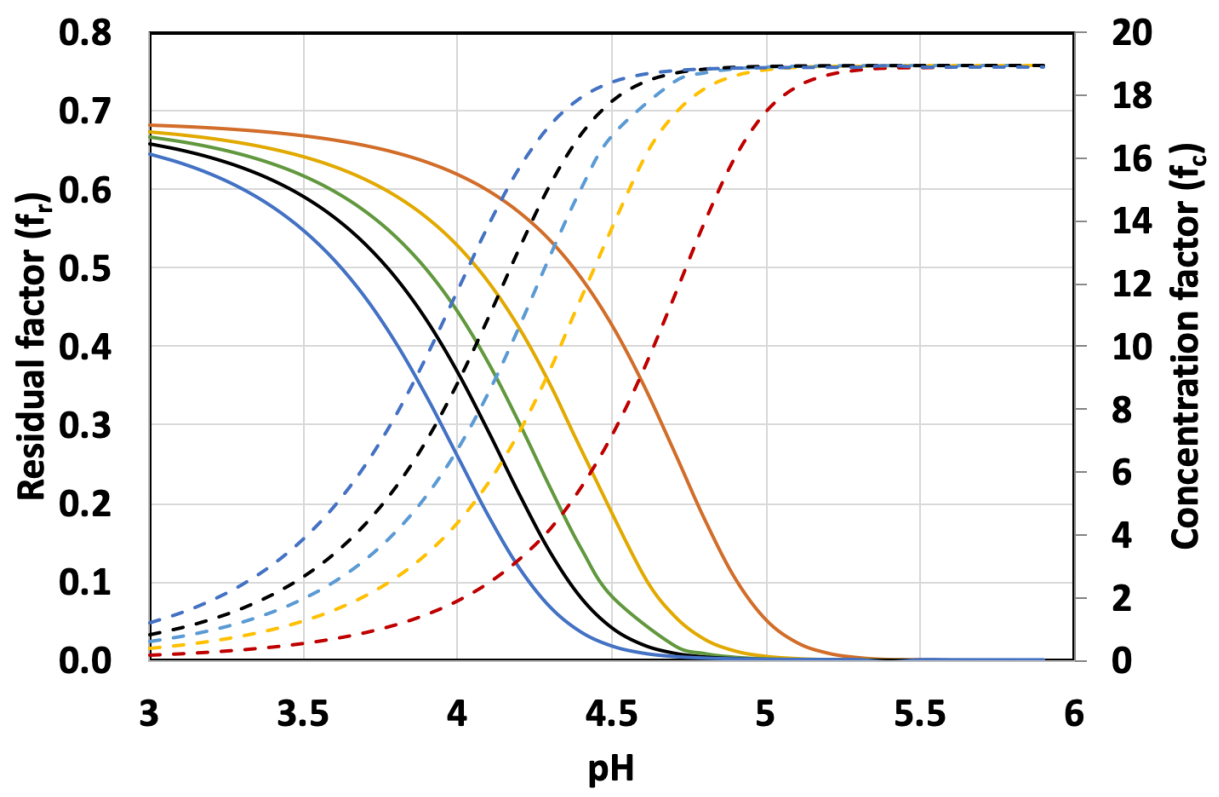

Figure 6: Influence of $\mathrm{pH}$ at various solvent flowrates on residual factor $\left(\mathrm{f}_{\mathrm{r}}\right)$ and concentration factor $\left(f_{c}\right)$ for flowsheets $2 \_1$. Operating parameters: $\mathrm{x}_{0}=1.7 \mathrm{~g} \mathrm{~L}^{-1} ; \mathrm{x}_{\text {strip }}=0$; stripping solution: pH 1 and $\left[\mathrm{Cl}^{-}\right]=1 \mathrm{~mol} \mathrm{~L}^{-1}$; feed flowrate $\mathrm{F}=110 \mathrm{~m}^{3} \mathrm{~h}^{-1}$; stripping flowrate $=4 \mathrm{~m}^{3} \mathrm{~h}^{-1}$. - : solid line=Residual factor; ---: dotted line=Concentration factor; red: $\mathrm{S}=30 \mathrm{~m}^{3} \mathrm{~h}^{-1}$; yellow: $\mathrm{S}=70 \mathrm{~m}^{3}$ $\mathrm{h}^{-1}$; green: $\mathrm{S}=110 \mathrm{~m}^{3} \mathrm{~h}^{-1}$; black: $\mathrm{S}=30 \mathrm{~m}^{3} \mathrm{~h}^{-1}$; blue: $\mathrm{S}=220 \mathrm{~m}^{3} \mathrm{~h}^{-1}$. Calculated data from from Eqs (1)-(6) with the physicochemical parameters reported in Table 1. 
(a)
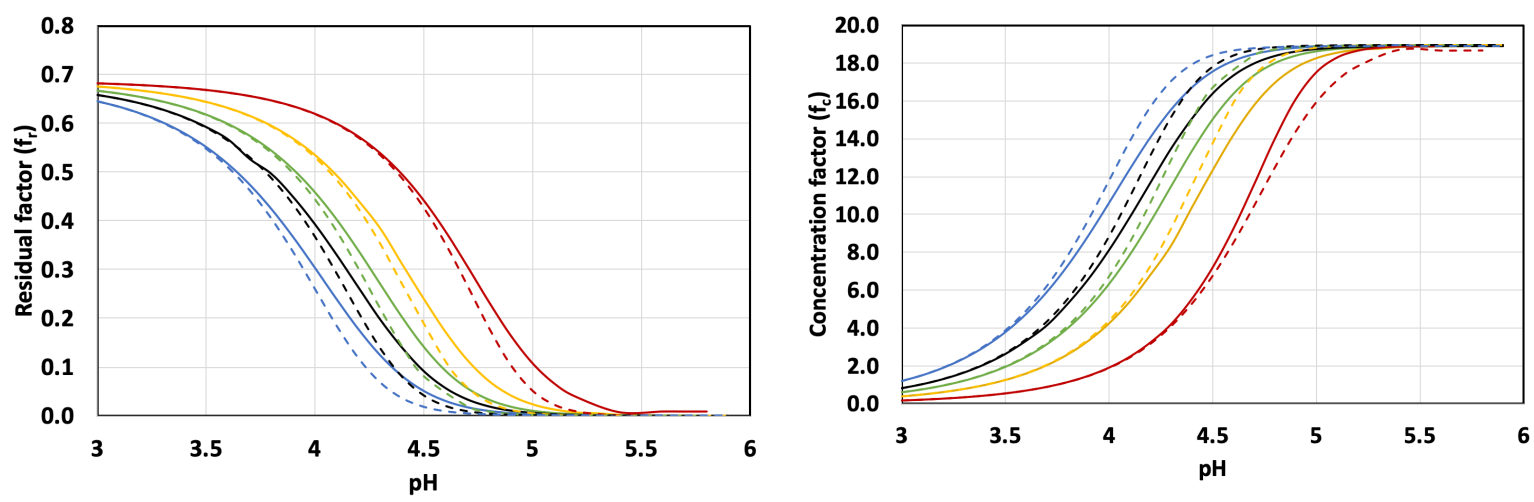

(b)
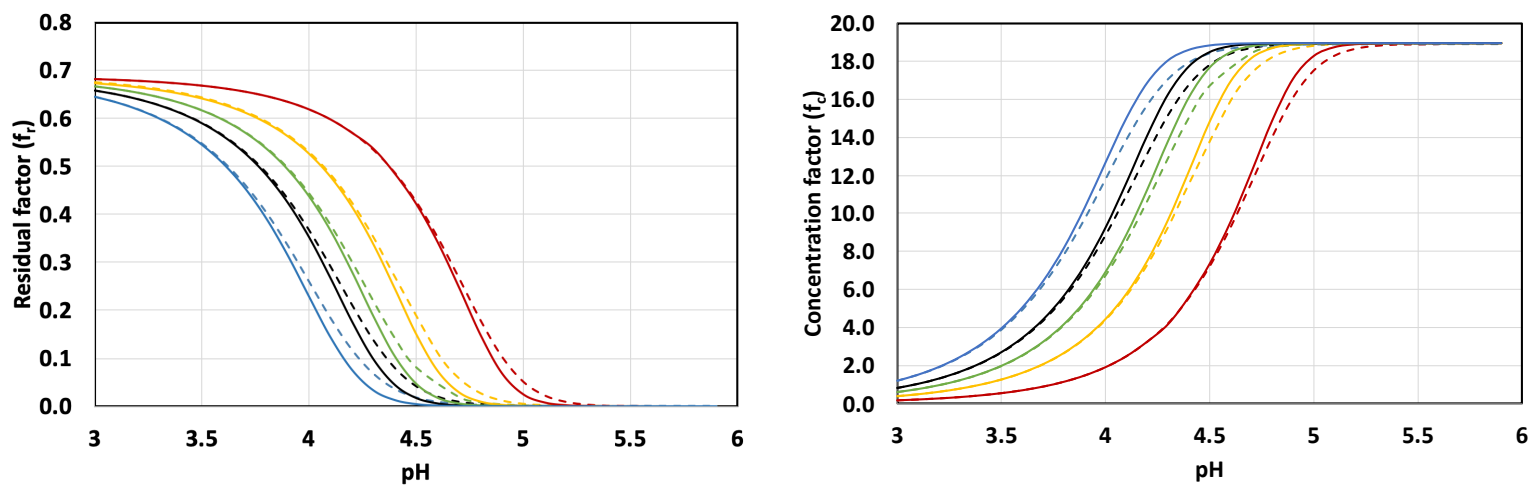

Figure 7: Comparison of Residual fraction $\left(f_{r}\right)$ and concentration fraction $\left(f_{c}\right)$ between flowsheets (a) 2_1 (solid lines) and 3_1 (dotted lines) and (b) 3_1 (solid lines) and 4_3 (doted lines) as a function of $\mathrm{pH}$ at various solvent flowrates (S). Operating parameters: $\mathrm{x}_{0}=1.7 \mathrm{~g} \mathrm{~L}^{-1}$; $\mathrm{X}_{\text {strip }}=0$; stripping solution: $\mathrm{pH} 1$ and $\left[\mathrm{Cl}^{-}\right]=1 \mathrm{~mol} \mathrm{~L}^{-1}$; feed flowrate $\mathrm{F}=110 \mathrm{~m}^{3} \mathrm{~h}^{-1}$; stripping flowrate $=4 \mathrm{~m}^{3} \mathrm{~h}^{-1}$; red: $\mathrm{S}=30 \mathrm{~m}^{3} \mathrm{~h}^{-1}$; yellow: $\mathrm{S}=70 \mathrm{~m}^{3} \mathrm{~h}^{-1}$; green: $\mathrm{S}=110 \mathrm{~m}^{3} \mathrm{~h}^{-1}$; black: $\mathrm{S}=30 \mathrm{~m}^{3}$ $\mathrm{h}^{-1}$; blue: $\mathrm{S}=220 \mathrm{~m}^{3} \mathrm{~h}^{-1}$. Calculated data from from Eqs (1)-(6) with the physicochemical parameters reported in Table 1. 
(a)

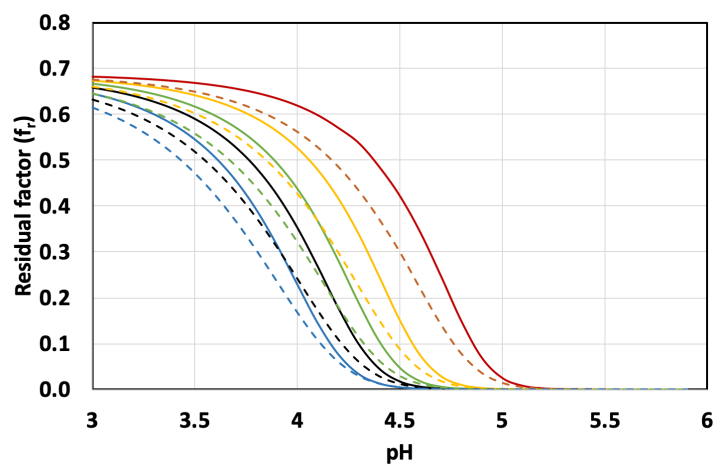

(b)

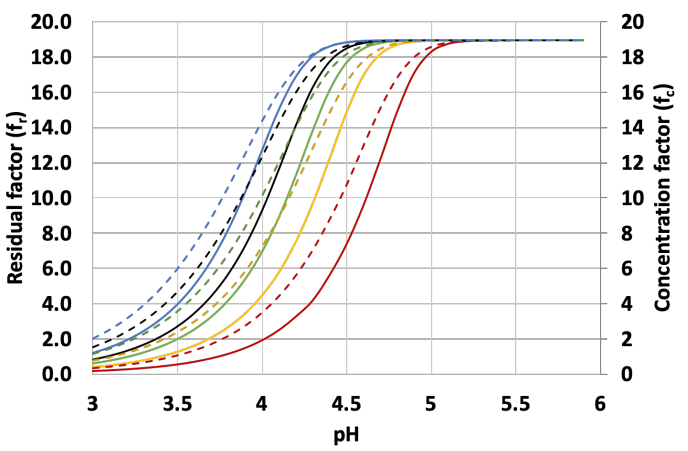

Figure 8: Comparison of (a) Residual fraction $\left(f_{r}\right)$ and (b) concentration fraction $\left(f_{c}\right)$ between flowsheets $4 \_3$ (solid line) and 13_12 (dotted line) as a function of $\mathrm{pH}$ at various solvent flowrates (S). Operating parameters: $\mathrm{x}_{0}=1.7 \mathrm{~g} \mathrm{~L}^{-1}$; $\mathrm{x}_{\text {strip }}=0$; stripping solution: $\mathrm{pH} 1$ and $\left[\mathrm{Cl}^{-}\right]=1$ mol L $\mathrm{L}^{-1}$; feed flowrate $\mathrm{F}=110 \mathrm{~m}^{3} \mathrm{~h}^{-1}$; stripping flowrate $=4 \mathrm{~m}^{3} \mathrm{~h}^{-1}$; yellow: $\mathrm{S}=70 \mathrm{~m}^{3} \mathrm{~h}^{-1}$; green: $\mathrm{S}=110 \mathrm{~m}^{3} \mathrm{~h}^{-1}$; black: $\mathrm{S}=150 \mathrm{~m}^{3} \mathrm{~h}^{-1}$; blue: $\mathrm{S}=220 \mathrm{~m}^{3} \mathrm{~h}^{-1}$. Calculated data from from Eqs (1)-(6) with the physicochemical parameters reported in Table 1.

(a)

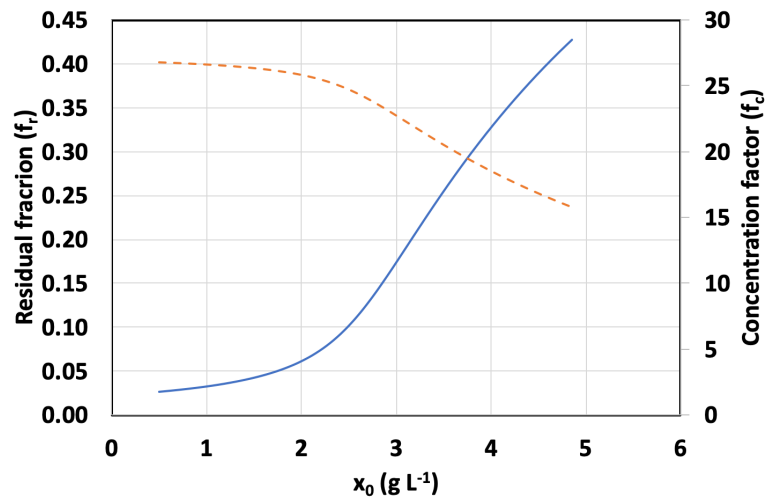

(b)

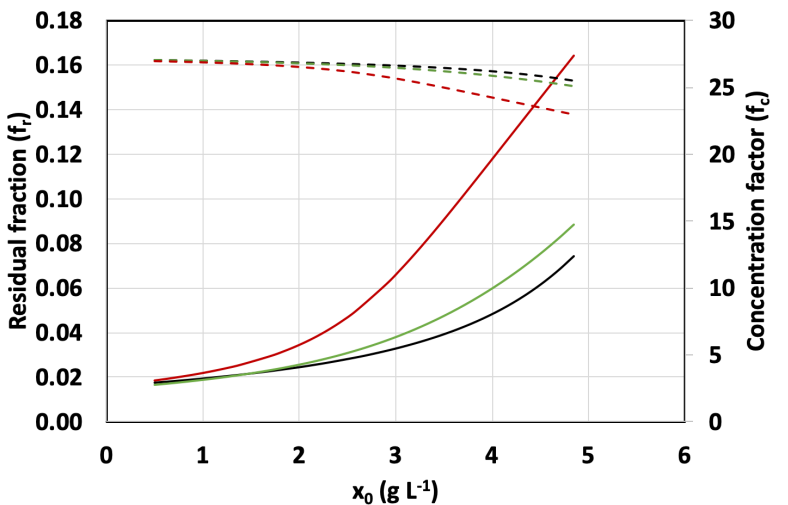

Figure 9: Influence of cobalt concentration in the leach solution $\left(x_{0}\right)$ on residual fraction (solid line) and concentration factor (dotted line) at pH 5 for flowsheets (a) $4 \_3$ and (b) 13_12 or 13_21 (black), 22_12 or 22_21 (green) and 31_12 or 31_21 (red). Operating parameters: Leach solution: $\mathrm{pH}=5$ and $\left[\mathrm{Cl}^{-}\right]=1 \mathrm{~mol} \mathrm{~L}^{-1}$; Stripping solution: $\mathrm{pH} 1$ and $\left[\mathrm{Cl}^{-}\right]=1 \mathrm{~mol} \mathrm{~L}^{-1} ; \mathrm{F}=110 \mathrm{~m}^{3} \mathrm{~h}^{-}$ 1; $\mathrm{S}=30 \mathrm{~m}^{3} \mathrm{~h}^{-1}$ and $\mathrm{F}^{\prime}=4 \mathrm{~m}^{3} \mathrm{~h}^{-1}$. Calculated data from from Eqs (1)-(6) with the physicochemical parameters reported in Table 1. 
